\title{
O NACIONALISMO EM ONDE CANTAO SABIÁ, DE GASTÃO TOJEIRO
}

\author{
Cássio Gustavo Busetto*
}

\section{Apresentação}

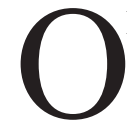

Modernismo Brasileiro foi certamente o mais vigoroso movimento artístico no país, no sentido de renovar valores estéticos e repensar o Brasil desde uma perspectiva histórico-cultural mais crítica. Nesse sentido, a Semana de Arte Moderna foi um marco, embora muitas manifestações anteriores ${ }^{1}$ indicavam uma busca consciente por substituir valores e critérios já superados.

Quase todas as artes estavam representadas no grupo modernista, exceto a nossa dramaturgia. Não havia sequer um dramaturgo ligado ao grupo de 1922, e mesmo Oswald de Andrade, que anos antes publicara com Guilherme de Almeida um pequeno volume com duas peças escritas em francês, ${ }^{2}$ só publicaria sua

* Universidade Federal do Paraná.

1 Francisco Iglésias considera o ano de 1912 como digno de referência, com a chegada do futurismo pelas mãos de Oswald de Andrade (ÁVILA, 1975, p. 14).

2 Wilson Martins comenta a respeito das comédias de Oswald de Andrade: "Os brasileiros (...) estavam escrevendo (...) também frívolas comédias parisienses de boulevard, como os futuros modernistas Guilherme de Almeida (1890-1969) e Oswald de Andrade com o Théâtre Brésilien, discretamente omitido das obras chamadas 'completas' e, por definição, tropicalistas, deste último. O pequeno volume, impresso em 1916 (...) compunha-se de 'Mon cœur balance', comédia em quatro atos, e 'Leur âme', em três atos e quatro quadros" (MARTINS, 1996, p. 36). 
BUSETTO, C. G. O nacionalismo em Onde canta o sabiá...

famosa peça modernista $O$ rei da vela em 1937, escrita quatro anos antes, e que só seria representada pela primeira vez quase três décadas mais tarde.

O estudioso Décio Prado ${ }^{3}$ observa a ausência de representantes da nossa dramaturgia no movimento modernista, e que a renovação de nosso teatro iniciarse-ia quase duas décadas depois, com Vestido de Noiva, de Nelson Rodrigues. $\mathrm{O}$ autor chama a atenção para a atividade crítica de Antônio de Alcântara Machado, que em seus artigos não se limita à apreciação da produção teatral da época, mas prega valores que não encontra em nossos palcos, "condenando em sua totalidade o presente em nome de um futuro que se pretende instaurar". ${ }^{4}$ Esse futuro, no entanto, tarda em chegar, e a voz de Alcântara Machado representa o inconformismo de um criador que não vê lugar para suas concepções dramáticas, e que não vai encontrar eco na produção teatral de seu tempo.

Assim, não podemos falar em um teatro modernista no começo da década de 1920 ou no período subseqüente, já que a produção teatral desse período compunha-se quase totalmente de comédias de costumes ligeiras e dramas amorosos. Uma obra representativa desse período é Onde canta o sabiá, de Gastão Tojeiro, encenada pela primeira vez em 1921, no Teatro Trianon. Essa peça, aliás, é considerada um modelo de sua categoria, o chamado Gênero Trianon..$^{5}$

Embora em nada o autor se preocupe com uma estética modernista, encontramos nessa peça uma temática cara aos artistas que promoveram a Semana: o nacionalismo, que passados os primeiros anos de vida republicana toma novo fôlego e nova dimensão após a crise de valores suscitada pela Primeira Guerra Mundial.

Neste artigo, pretendemos analisar o nacionalismo na peça de Tojeiro, de como ele é fruto antes de um sentimento difuso de euforia que tomava conta das elites brasileiras, no afã de construir uma imagem de brasilidade, que da reflexão

3 PRADO, D. de A. O Teatro. In: ÁVILA, A. (Org.). O Modernismo. São Paulo: Perspectiva, 1975 .

4 Ibid., p. 140.

5 O chamado "Gênero Trianon" ou "teatro de boulevard" era um gênero de teatro ligeiro, sem maiores pretensões, feito exclusivamente para rir. Por conta dos sucessos de autores como Joracy Carmargo, Armando Gonzaga, Raimundo Magalhães Jr. e o próprio Gastão Tojeiro, entre outros, apresentados no Teatro Trianon, é que o gênero tem esse nome. Segundo CAFEZEIRO e GADELHA, "a continuidade ao filão das comédias de costumes, de presença tão expressiva entre nós desde o Século XIX".

CAFEZEIRO, E.; GADELHA, C. História do teatro brasileiro: de Anchieta a Nelson Rodrigues. Rio de Janeiro: Editora da UFRJ, 1996. p. $347 . \quad$ [c/ autor: outra nota?] 
cuidadosa da realidade nacional na busca de uma identidade, talvez a principal preocupação do grupo de $1922 .{ }^{6}$

\section{As origens do nacionalismo}

Segundo Skidmore (1998), após a proclamação da república, em 1889, as elites brasileiras estavam preocupadas em criar um novo país, mais moderno, que estivesse alinhado às conquistas e avanços do mundo exterior. $\mathrm{O}$ Brasil tornar-se-ia uma federação, e a ordem era descentralizar e estimular os estados economicamente mais dinâmicos, como São Paulo, a dirigir seu próprio desenvolvimento. O poder claramente passava às mãos das oligarquias dos principais estados, e novos símbolos foram criados "para celebrar o ingresso do Brasil no mundo sem monarcas".?

Além disso, uma nova imagem do Brasil começou a ser criada, tanto interna como externamente. Um novo projeto de país estava surgindo, cujos objetivos eram criar uma nova identidade nacional, desprendida do ranço monarquista, e apresentar ao mundo uma imagem muito mais atraente para conseguir mais investimentos, pois se assomava como parceiro econômico em igualdade.

Nesse sentido, buscou-se uma europeização das cidades brasileiras, em particular o Rio de Janeiro, e Paris sempre foi um modelo indiscutível das elites. No começo do século XX houve uma grande reconstrução do centro da capital federal, e dois amplos boulevards foram construídos a partir das docas. Muitos cortiços foram destruídos, e muitas famílias de trabalhadores foram forçadas a encontrar novos alojamentos, distantes, muitas vezes, de seus trabalhos. $\mathrm{O}$ centro do Rio ficava livre das classes mais baixas, e novos edifícios públicos, como a Biblioteca Nacional e o Teatro Municipal (inspirado na Ópera de Paris), foram construídos. A própria elite se referia a esse programa de reconstrução como o Rio civilizando-se. Essa idéia de civilização opunha-se a um passado colonial e imperial, cujo modelo fracassara e já não atendia aos anseios dessa elite, que o via como um anacronismo e um empecilho ao progresso nacional.

6 MORAES, E. J. A questão da brasilidade. In: A brasilidade modernista: sua dimensão filosófica. Rio de Janeiro: Graal, 1978.

7 SKIDMORE, T. E. Uma história do Brasil. 2. ed. São Paulo: Paz e Terra, 1998. p. 109 . 
Nas primeiras décadas do século XX empreendeu-se o desbravamento do interior do país, onde chegavam levas de exploradores estrangeiros atraídos pelas histórias de riquezas naturais e minerais. Além disso, um incipiente processo de industrialização tomava fôlego, não obstante a falta de políticas públicas definidas para o setor, pois a maioria da elite política acreditava que isso ia de encontro aos interesses de longo prazo do Brasil. A industrialização deu-se como conseqüência indireta de outras políticas governamentais, como as altas tarifas de importação. Em 1910, por exemplo, São Paulo tomava o rumo que o levaria a ser o grande parque industrial dos anos 60, como líder da modernização: "São Paulo estava também na vanguarda se tomarmos por critérios de modernização educação pública, instalações sanitárias e transportes. Isso dava aos paulistas um sentimento de superioridade quanto ao resto do Brasil". ${ }^{8}$ Não é de estranhar, pois, que os idealizadores da Semana vissem em São Paulo um exemplo para o país, e consideravam o estado como o grande símbolo da modernidade e imagem do país futuro.

Embora houvessem diminuído as exportações de seus principais produtos - café e borracha -, e a ideologia econômica predominante condenasse a industrialização em prol da vocação agrária do país, no Brasil das primeiras décadas do século XX havia certo entusiasmo quanto à idéia de que o país estava rumo à modernização, e que poderia chegar a um padrão de vida próximo ou até mesmo igual aos países europeus e Estados Unidos.

No começo da década de 20, além das comemorações pelo centenário da Independência que se aproximava, a crise de valores que abalou a Europa no pós-guerra teria reflexos imediatos por aqui:

A elite brasileira sempre admirara a Europa, portanto a deflagração da Primeira Guerra Mundial foi recebida como um choque, fornecendo também um catalisador para os esforços do movimento nacionalista nascente no Brasil ao divulgar a doutrina de que o país só poderia sobreviver e prosperar reconhecendo e aproveitando o caráter específico de sua identidade. ${ }^{9}$

8 SKIDOMORE., op. cit., p. 119.

9 Ibid., p. 137. 
No ano de 1920 havia um clima de extremo otimismo, não obstante nossos problemas sociais, como greves e os obstáculos criados pela circulação monetária irregular, criando dificuldades para fazendeiros e industriais financiarem a produção. Mesmo assim, tais indícios da mudança dos tempos não foram suficientes para abalar a confiança depositada no regime político e no país pelas elites econômicas, políticas e até intelectuais. ${ }^{10} \mathrm{~A}$ esse respeito, o artigo publicado em 31 de maio de 1920 na revista Papel e Tinta, à cuja frente estavam Oswald de Andrade e Menotti del Picchia, citado por Brito (1997, p. 141), ilustra o clima de ufanismo que vivia a nação:

As conseqüências sociais da guerra refletiram-se singularmente na vida do nosso povo. Por esse instinto de progresso, que vigia na alma das nacionalidades, o Brasil, em cinco anos, sofreu uma transformação visceral. Todas as suas forças econômicas, políticas, intelectuais tiveram uma eclosão notável. Fixou a sua independência financeira; criou e deu definitiva viabilidade à sua indústria; o seu comércio, em vez de especular com a importação que empobrece, levou os produtos nacionais aos mercados estrangeiros; (...) as cidades, densas de uma população ávida de trabalho, tornaram-se centros febricitantes de progresso e riqueza.

Podemos notar que esta é uma visão mais do que otimista da realidade da época: o Brasil não conquistara sua independência financeira, pois ainda dependia de grande quantidade de investimentos externos; a industrialização ocorreu à revelia do governo federal, pois não houve nenhum programa substancial de incentivo à produção industrial e sua manutenção; os comerciantes urbanos eram contrários à industrialização, pois obtinham lucros extraordinários justamente das importações; além disso, o Brasil perdera o monopólio da exportação de borracha e viu diminuírem sensivelmente as exportações de café. ${ }^{11}$

Mesmo assim, havia a sensação de que o Brasil estava no caminho certo rumo ao futuro, que se apresentava grandioso e promissor. Nada poderia deter a pujança de um país que ansiava crescer e desenvolver-se, para finalmente abandonar o século XIX e ingressar no século XX.

10 BRITO, M. da S. História do modernismo brasileiro 1: antecedentes da Semana de Arte Moderna. 6. ed. Rio de Janeiro: Civilização Brasileira, 1997. p. 139-140.

11 SKIDMORE, op. cit., cap. 5. 


\section{O nacionalismo ufanista de Tojeiro}

É nesse clima de euforia que surge Onde canta o sabiá. Desde o título, que remete ao famoso poema Canção do Exílio, de Gonçalves Dias - poema romântico em que o eu-lírico ufana-se das belezas naturais do país -, a peça tenta consolidar, de modo pouco consistente e sem muita clareza, um conjunto de valores que expressem o sentimento da época: de um país que finalmente encontrou sua identidade como nação, e que poderia encarar em pé de igualdade os países desenvolvidos. Através da comédia de costumes, Tojeiro tenta fazer um retrato da sociedade da época, satirizando "os hábitos característicos da nossa organização social e política, aliada à idéia de que, apesar de tudo, o Brasil é o melhor país do mundo e que aqui se encontram as possibilidades futuras". ${ }^{12}$

Assim, Tojeiro

retrata a vida pacata de uma família de classe média de subúrbio carioca e a quebra da monotonia com as chegadas e partidas de trens. A família pequeno-burguesa: marido, mulher, casal de filhos casados; uma filha e uma enteada para casar; um sobrinho desempregado; um casal de criados. O problema que mais aflige a família é o desemprego do sobrinho, não muito disposto a enfrentar o batente. Ao iniciar a peça, estão todos na expectativa de entregar uma carta ao ministro, o Dr. Amarante. O patriarca passa a sua pacata vidinha a observar o trabalho de seu jardineiro; as discussões dos membros da família quase sempre divididos em grupos; os namoros das meninas; os galanteios dos primos. A vida se transforma com a chegada do circo de cavalinhos ou de algum novo funcionário da estação da Estrada de Ferro. (Cafezeiro; Gadelha, 1996, p. 347-348)

Imbuído desse sentimento de revelar e fixar valores, satiriza a tentativa de o sobrinho preguiçoso, Ernani, conseguir um emprego público através de uma indicação do ministro. Não se admite mais esse tipo de atitude, embora Fabrino, genro de Justino e Inácia, os pais da família em questão, também tenha

12 MAGALDI, S. Panorama do teatro brasileiro. 3. ed. São Paulo: Global, 1997. p. 192. 
BUSETTO, C. G. O nacionalismo em Onde canta o sabiá...

conseguido um emprego dessa maneira, e por isso mesmo é admoestado por sua sogra:

\author{
Fabrino - Não tenho feitio para pedir. (Levanta-se \\ do sofá e vai sentar-se na cadeira de balanço). \\ Inácia - Não tem feitio para pedir, hein? Mas quando você \\ quis arranjar o emprego que tem, andou a empenhar- \\ se com Deus e todo mundo. Não me faça falar, que \\ é o melhor! (Tojeiro, 1973, p. 5)
}

Mas algo perturba a tranqüilidade da casa: a chegada de Elvídio, amigo de Fabrino que retorna ao país após longa temporada em Paris, e que incorporara o estilo de vida da capital francesa. Havia 14 anos que não se viam os dois amigos, e é revelador seu encontro, na medida em que já estabelece a oposição entre valores nacionais e europeus. Fabrino, após tanto tempo, casara-se com Virgínia, e abandonara os tempos de farra e boemia:

\author{
Elvídio - Então, que é feito de ti? \\ Fabrino - Aqui onde me vês. Já não sou o Fabrino que \\ conheceste há 14 anos, estróina inveterado como tu, \\ o implacável inimigo da santa instituição do lar, da \\ família. (Tojeiro, 1973, p. 23)
}

Como seria natural, passaram-lhe as extravagâncias da juventude, e agora amadurecera. Já Elvídio permanece da mesma maneira como há 14 anos, tem as mesmas idéias, e ainda não superou a fase do hedonismo juvenil, apesar do tempo transcorrido. Temos, com Fabrino, uma analogia com a jovem república, que vai ao encontro da idéia de que o Brasil começava atingir sua maturidade, preservando e cultivando os valores considerados sólidos, como a família.

Elvídio desdenha tudo que seja nacional, enaltecendo as qualidades de Paris e minimizando os efeitos devastadores da guerra terminada dois anos 
BUSETTO, C. G. O nacionalismo em Onde canta o sabiá...

antes (a história se passa em 1920, segundo indicação do início da peça), em mais uma demonstração de leviandade:

\begin{tabular}{|c|c|}
\hline Elvídio & $\begin{array}{l}\text { - ... Só pode gostar disto quem não conhece a Europa } \\
\text { com toda sua requintada civilização. }\end{array}$ \\
\hline Fabrino & depois da guerra? \\
\hline Elvíd & $\begin{array}{l}\text { - Ora, a guerra!... A guerra já se foi há muito e Paris, } \\
\text { o nosso incomparável Paris já retomou seu aspecto } \\
\text { habitual. Creia, meu amigo, só na Europa se vive. } \\
\text { Aqui vegeta-se. Mais do que isso: estiola-se o físico } \\
\text { e o espírito. Isto aqui não vale o pior lugarejo da } \\
\text { Europa. }\end{array}$ \\
\hline Fabrino & $\begin{array}{l}\text { - Eu já penso justamente o contrário. (Tojeiro, } \\
\text { 1973, p. 24) }\end{array}$ \\
\hline
\end{tabular}

Como questiona Fabrino, mesmo com sua "requintada civilização" a Europa produziu uma guerra cruel e absurda, como há muito não se via, ${ }^{13}$ incompatível com o conceito de "civilização", e a atitude alienada de Elvídio aponta para uma cultura de valores decadentes. Sobre isso escreve Mônica Velloso:

O clima do primeiro pós-guerra determina alterações fundamentais na forma de se pensar o Brasil. Modificado o quadro internacional, altera-se conseqüentemente a configuração da parte Brasil. A crise de valores que sacode o cenário europeu tem seus reflexos imediatos aqui. Recorrendo às metáforas organicistas, nossos intelectuais exprimem a idéia da velha e da nova civilização: o Brasil é o organismo sadio e jovem, enquanto a Europa é a nação decadente que deve fatalmente ceder lugar à América triunfante. Alguns intelectuais interpretam o contexto como uma confirmação da análise (...) que previa o fim da cultura européia e a aurora do novo mundo. (Velloso, 1993, p. 89)

13 O último conflito continental a abalar a Europa haviam sido as Guerras Napoleônicas, terminadas em 1815. 
Além disso, Elvídio se refere ao amigo como “romântico indígena”, pelo fato de este ter se apaixonado por Virgínia, em mais uma referência aos mitos do nacionalismo romântico, que Tojeiro tenta recuperar. Se os modernistas procuravam superar a idéia romântica de nação, atualizando nossa cultura na luta contra os gêneros literários considerados ultrapassados, Tojeiro ainda insiste em tal ideal, transplantando-o e adaptando-o para seu momento histórico. Os modernistas acreditavam que para modernizar o país era necessário conhecê-lo, considerando suas peculiaridades e propriedades. O ingresso na modernidade deveria necessariamente ser mediado pelo nacional, e a grande questão que se colocava era dar conta desse nacional. ${ }^{14}$

Tojeiro, sem nenhuma preocupação dessa natureza, passa ao largo desse tipo de reflexão, já que se exime da tarefa de tentar dar conta desse nacional. Limita-se à oposição nacional versus europeu, em que uma velha aristocracia, representada por Elvídio, ainda insiste em olhar em direção ao velho continente, como um modelo de valores e de vida. Elvídio é "simplesmente um homem saturado de civilização" (aqui, civilização novamente indica os decadentes valores europeus, que produziram as barbáries da guerra), não trabalha, vive de sua fortuna, e voltara ao Brasil para vender as últimas propriedades que aqui possuía para mudar-se definitivamente a Paris.

Não há qualquer busca ou reflexão sobre a construção da brasilidade, é como se ela já existisse e só faltasse a Elvídio descobri-la, independentemente do elemento humano que aqui se encontra. Os encantos, como no poema de Gonçalves Dias, já estão cá:

Justino - A coisa é o seguinte: quando a gente passa muito
tempo fora de sua terra, esquece-a; mas depois,
voltando, identifica-se novamente com o meio,
reavivando as antigas amizades, criando outras novas,
e assim torna-se a gostar da terra que nos foi berço,
mesmo com todos os seus defeitos.
Elvídio -
Fabrimo de acordo...
- Tal e qual como certos homens, que ao abandonarem
as suas amantes, acham que elas são defeituosas,
insuportáveis, jurando nunca mais as verem. Tempos
depois, ao reencontrar alguma, após alguns

14 VELLOSO, M. P. A brasilidade verde-amarela: nacionalismo e regionalismo paulista. Estudos Históricos, Rio de Janeiro, vol. 6, n. 11, p. 89-112, 1993. 
BUSETTO, C. G. O nacionalismo em Onde canta o sabiá...

momentos de conversa, começa ele a achar-lhe qualidades e encantos, que antes nunca lhe descobrira ou mesmo porque então ela não os possuísse... E não tardam em caírem um nos braços do outro. (Tojeiro, 1973, p. 28-29)

Os encantos da terra lhe são inerentes e irresistíveis, não há como oporse-lhes. E mesmo Elvídio admite essa possibilidade: diante da comparação de Fabrino, afirma que isso não se dará com ele devido ao pouquíssimo tempo que tenciona ficar na terra pátria, não se permitindo seduzir pelas belezas locais.

No entanto, Elvídio acaba por sucumbir aos encantos não da terra pátria, mas de Nair, cunhada de Fabrino. Após conhecerem-se, numa ocasião em que discutem por conta da exacerbada francofilia de Elvídio, este se apaixona perdidamente pela moça. Ela, entretanto, nutre certa antipatia pelo rapaz. Quando ele se encontra a sós com Nair, pouco antes de declarar-lhe seu amor, diz ter percebido, por ser um profundo conhecedor da alma feminina, a antipatia que lhe desperta. E ele admite que tal conhecimento só lhe fora possível pelas inúmeras aventuras amorosas que tivera na Europa. E Tojeiro não poderia ser mais explícito: Paris é terra da libertinagem, da falta de valores morais, enquanto que aqui cultivamos os bons e saudáveis valores familiares, na voz da própria Nair:

Nair - Pensava que todas as suas aventuras lhe seriam possíveis? Engana-se. Volte para o seu Paris, que é o campo propício às suas libertinagens. Nós aqui ainda não atingimos a essa perfeição de que o sr. tanto fala... (Tojeiro, 1973, p. 50)

Mas Elvídio já está fascinado por Nair, e indiretamente, por seu país. Os encantos de ambos - de Nair e do Brasil - confundem-se, visto que o verdadeiro amor não seria possível no ambiente libertino parisiense, e amar Nair implica necessariamente amar o Brasil. Só mesmo aqui, com valores familiares e morais sólidos, é possível o amor puro e verdadeiro, em mais uma demonstração passadista de romantismo. Elvídio, que tanto detestava seu país, já está propenso a mudar de idéia, pois nunca antes estivera tão apaixonado, e isso lhe motiva 
uma transformação, já que não encontrara o verdadeiro amor nos tantos anos que passara em Paris. Passa a ver com outros olhos o país que lhe proporciona tal sentimento, e tal como as palavras proféticas de Justino e Fabrino, passa a descobrir novas qualidades na terra pátria.

Nair, apesar de a princípio antipatizar com Elvídio, acaba por também apaixonar-se pelo rapaz, e sofre por tê-lo rejeitado. É quando o sabiá, numa metáfora bastante óbvia, foge da gaiola, e já não canta mais. A moça agora sofre ainda mais, pois Elvídio reforça sua decisão de voltar à Europa o mais rápido possível, não mais por detestar o Brasil, mas para fugir da desilusão amorosa.

Mas como nenhum conflito é realmente um conflito na peça de Tojeiro, apenas pretexto para desfilar suas patriotices e cacoetes românticos, os dois terminam por reconciliar-se, quando Elvídio, numa última investida, procura Nair para despedir-se, numa cena em que os excessos do romantismo são desfilados sem maiores constrangimentos:

\begin{tabular}{|c|c|}
\hline Jair & $\begin{array}{l}\text { - Mas para que parte assim tão precipitadamente? } \\
\text { Podia se demorar mais... }\end{array}$ \\
\hline Elvídio & $\begin{array}{l}\text { - Não posso. Sofro muito!... Preciso partir, } \\
\text { desaparecer, tendo a certeza de que uma grande } \\
\text { distância me separa daquela que jamais me } \\
\text { pertencerá! }\end{array}$ \\
\hline Nair & $\begin{array}{l}\text { - Não vá nesse vapor... Tenho o pressentimento que } \\
\text { lhe vai suceder alguma desgraça... Um naufrágio... }\end{array}$ \\
\hline Elvíd & $\begin{array}{l}\text { - É o que eu desejaria! Para que mais viver? Já conheci } \\
\text { todos os prazeres da vida. Quando finalmente julgava } \\
\text { realizar a minha felicidade, sou repelido como se } \\
\text { fora o maior criminoso! (Tojeiro, 1973, p. } 72 \text { ) }\end{array}$ \\
\hline
\end{tabular}

Nair também acaba por confessar seu amor por Elvídio, e ambos se entregam a um beijo apaixonado, sob a luz forte do luar. É quando o sabiá, que fora capturado pelo chefe da estação, volta a cantar. Está refeita a harmonia da casa, e agora Elvídio ama fervorosamente o Brasil. O amor de Nair lhe desperta um nacionalismo súbito e imotivado, pois ele bem poderia casar-se com a moça e ambos mudarem-se para Paris. Mas não é o que acontece, pois, para preservar 
BUSETTO, C. G. O nacionalismo em Onde canta o sabiá...

um mínimo de organicidade da peça e reafirmar o nacionalismo gratuito e inconsistente de Tojeiro, é necessário reforçar a coesão familiar, e, para tal, Elvídio precisa integrar-se ao clã de Justino e Inácia. Os decadentes valores europeus que o rapaz encarna e proclama sucumbem, assim, aos mais autênticos valores nacionais.

Como julgara o ex-parisiense, após experimentar todos os prazeres da vida, só é possível a felicidade na casa onde canta o sabiá. Elvídio já não é o "estróina" hedonista do início da comédia, pois deixara-se apaixonar, sentimento que antes criticara em Fabrino. Houve uma revisão de seus conceitos, e agora se redime através do amor:

Fabrino (Vindo a Elvídio) - Então, seu celibatário de uma figa, eu só que sou o retrógrado?

Elvídio - Teorias, meu velho, teorias que falham ao primeiro contacto (sic) da realidade. (Tojeiro, 1973, p. 75)

Elvídio aceita agora sua pátria, e essa aceitação implica em também aceitar seus valores morais. Se ele antes viveu longos anos apregoando teorias que falharam ao contato da realidade, esta só pode ser entendida como a vida nacional, onde a felicidade e o futuro são possíveis. A vida anterior não pode ser entendida como realidade, pois não permitiriam a verdadeira felicidade que Elvídio proclama ter encontrado, apesar dos prazeres que lhe proporcionara. Como o filho pródigo, volta à pátria para reconciliar-se com sua origem e sua gente.

\section{Últimas considerações}

Se a renovação modernista tardou em chegar a nossos palcos, Tojeiro não foi uma das vozes que por ela ansiavam. O nacionalismo de Onde canta o sabiá não consegue ultrapassar as barreiras da visão mecânica e maniqueísta impostas pelas exigências imediatas de seu tempo, e o autor não hesitou em esquivar-se de uma reflexão mais cuidadosa e menos apaixonada da realidade momentânea de sua época. 
Nesse sentido, a peça pode ser considerada como um instantâneo da euforia nacionalista do começo dos anos 20, aproveitando-se do assunto da moda. Prova disso é que Tojeiro não voltaria mais ao tema, e manter-se-ia fiel a seu estilo leve e pouco original. ${ }^{15} \mathrm{O}$ grande público de então, marcadamente $o$ carioca, queria ver representado o orgulho nacional, sem que isso implicasse um exame atento das causas e efeitos da onda nacionalista surgida no pós-guerra. Talvez seja esse o único mérito de Tojeiro: o de fixar um momento bastante particular, quando o sentimento nacionalista não dominava apenas o debate entre intelectuais, mas estava presente no cotidiano das pessoas da classe média pequeno-burguesa, como as personagens retratadas em Onde canta o sabiá. Assim, a peça já nasceu datada, ficando restrita ao ano de 1920, e seu valor é mais histórico que propriamente artístico, já que em nada contribuiu para o debate instaurado pelos modernistas sobre a construção da brasilidade.

Embora os modernistas também se tivessem deixado seduzir por essa euforia nacionalista do pós-guerra, foi-lhes mote para uma incursão sem precedentes na cultura brasileira, dando os primeiros passos na construção e compreensão de uma identidade nacional, alijada da visão alienante e alienada das correntes artísticas anteriores, particularmente o romantismo. Fazia-se necessário absorver os novos valores do século XX para atualizar a produção cultural brasileira, cabendo "à arte brasileira captar estes valores, registrando o dinamismo do momento. Porém, o processo de atualização nem sempre se dá de forma pacífica. Ele é conflituoso e às vezes chega a ser trágico, na medida em que implica a ruptura com nossos valores tradicionais". ${ }^{16}$

E é a atualização e a ruptura que são deliberadamente evitados por Tojeiro, em prol do riso leve e despreocupado. Se hoje ainda persiste, embora de modo menos intenso, a busca por uma identidade nacional, não de todo resolvida, Onde canta o sabiá não ajuda, per se, a entender como se deu o processo da construção da brasilidade no período modernista.

$15 \mathrm{Na}$ edição consultada de Onde canta o sabiá estão relacionadas as principais peças do autor, seguidas da indicação de gênero: quase todas são comédias ou burletas, que demonstram sua inclinação para o riso fácil.

16 VELLOSO, op. cit., p. 92. 
BUSETTO, C. G. O nacionalismo em Onde canta o sabiá...

\section{RESUMO}

A renovação artístico-cultural representada pelo Modernismo brasileiro tardou em chegar a nossos palcos. Nossos dramaturgos, apesar da efervescência cultural que o movimento causou, estavam alheios às inovações de forma e conteúdo que outras artes conheceram, pois ainda permaneciam ligados a uma tradição teatral própria do século XIX, apenas superada na década de 40. Um representante desse tipo de dramaturgia foi Gastão Tojeiro, e sua peça Onde canta o sabiá, escrita em 1920, pode ser considerada um exemplo da produção da época. Na peça, Tojeiro trata de um tema caro aos modernistas, o da identidade nacional. Mas se os artistas modernos estavam preocupados com uma revisão crítica dos valores nacionais, Tojeiro vai na contramão e se limita a reproduzir o nacionalismo romântico do século XIX.

Palavras-chave: teatro, modernismo, Brasil.

\section{RESUMEN}

La renovación artístico-cultural representada por el Modernismo Brasileño tardó en llegar a nuestros escenarios. Nuestros dramaturgos, a pesar de la efervescencia cultural que el movimiento causó, estaban ajenos a las innovaciones de forma y contenido que otras artes conocieron, pues aún estaban atados a una tradición teatral propia del siglo XIX, solamente superada en la década de 40. Un representante de ese tipo de dramaturgia fue Gastão Tojeiro, y su obra Onde canta o sabiá, escrita en 1920, puede ser considerada un ejemplo de la producción de aquella época. En esa obra, Tojeiro trata de un tema importante para los modernistas, el de la identidad nacional. Pero si los artistas modernos estaban preocupados con una revisión crítica de los valores nacionales, Tojeira va en la dirección opuesta, y se limita a reproducir el nacionalismo romántico del siglo XIX.

Palabras-clave: teatro, modernismo, Brasil.

\section{REFERÊNCIAS}

ÁVILA, A. (Org.). O Modernismo. São Paulo: Perspectiva, 1975.

BRITO, M. da S. História do modernismo brasileiro 1: antecedentes da Semana de Arte Moderna. 6. ed. Rio de Janeiro: Civilização Brasileira, 1997. 
BUSETTO, C. G. O nacionalismo em Onde canta o sabiá...

CAFEZEIRO, E.; GADELHA, C. História do teatro brasileiro: de Anchieta a Nelson Rodrigues. Rio de Janeiro: Editora da UFRJ, 1996.

COSTA, M. M. da. O modernismo segundo Mário de Andrade. In: ; et al. Estudos sobre o modernismo. Curitiba: Criar, 1982.

MAGALDI, S. Panorama do teatro brasileiro. 3 ed. São Paulo: Global, 1997.

MARTINS, W. História da inteligência brasileira (1915-1933). 2. ed. São Paulo: T. A. Queiroz, 1996. v. 6.

MORAES, E. J. A questão da brasilidade. In: A brasilidade modernista: sua dimensão filosófica. Rio de Janeiro: Graal, 1978.

SKIDMORE, T. E. Uma história do Brasil. 2. ed. São Paulo: Paz e Terra, 1998.

TOJEIRO, G. Onde canta o sabiá. Comédia em 3 atos. Rio de Janeiro: Serviço Nacional de Teatro, 1973.

VELLOSO, M. P. A brasilidade verde-amarela: nacionalismo e regionalismo paulista. Estudos Históricos, Rio de Janeiro, vol. 6, n. 11, p. 89-112, 1993. 